Document downloaded from:

http://hdl.handle.net/10251/176098

This paper must be cited as:

Blasco-Brusola, A.; Vayá Pérez, I.; Miranda Alonso, MÁ. (2020). Regioselectivity in the adiabatic photocleavage of DNA-based oxetanes. Organic \& Biomolecular Chemistry. 18(44):9117-9123. https://doi.org/10.1039/D0OB01974G

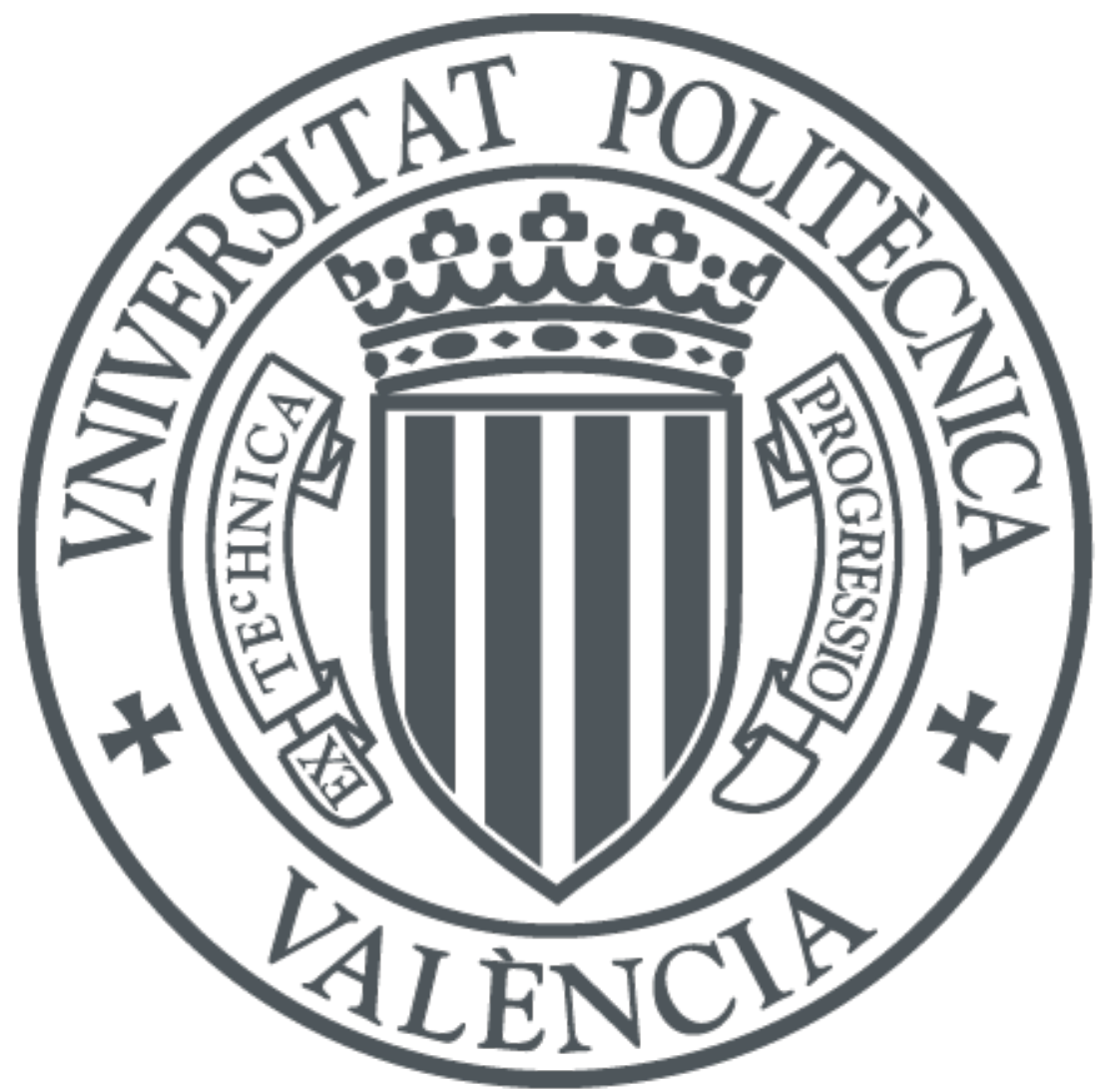

The final publication is available at

https://doi.org/10.1039/D0OB01974G

Copyright The Royal Society of Chemistry

Additional Information 


\title{
Regioselectivity in the adiabatic photocleavage of DNA-based oxetanes
}

Received 00th January 20xx, Accepted 00th January 20xx DOI: $10.1039 / \times 0 \times x 00000 x$

\begin{abstract}
Alejandro Blasco-Brusola, Ignacio Vayá* and Miguel A. Miranda*
Direct absorption of UVB light by DNA may induce formation of cyclobutane pyrimidine dimers and pyrimidine-pyrimidone (6-4) photoproducts. The latter arise from the rearrangement of unstable oxetane intermediates, which have also been proposed to be the electron acceptor species in the photoenzymatic repair of this type of DNA damage. In the present work, direct photolysis of oxetanes composed of substituted uracil (Ura) or thymine (Thy) derivatives and benzophenone (BP) have been investigated by means of transient absorption spectroscopy from the femtosecond to the microsecond time-scales. The results showed that photoinduced oxetane cleavage takes place through an adiabatic process leading to the triplet excited BP and the ground state nucleobase. This process was markedly affected by the oxetane regiochemistry (head-tohead, $\mathrm{HH}$, vs. head-to-tail, $\mathrm{HT}$ ) and by the nucleobase substitution; it was nearly quantitative for all investigated $\mathrm{HH}$-oxetanes while it became strongly influenced by the substitution at positions 1 and 5 for the HT-isomers. The obtained results clearly confirm the generality of the adiabatic photoinduced cleavage of BP/Ura or Thy oxetanes, as well as its dependence on the regiochemistry, supporting the involvement of triplet exciplexes. As a matter of fact, when formation of this species was favored by keeping together the Thy and BP units after splitting by means of a linear linker, a transient absorption at $\sim 400$ $\mathrm{nm}$, ascribed to the exciplex, was detected.
\end{abstract}

\section{Introduction}

The origin of human diseases such as skin cancer can be associated in many cases to photoinduced DNA damage..$^{1-3}$ Thus, when DNA absorbs UV light, a cascade of reactions may lead to the formation of cyclobutane pyrimidine dimers (CPDs) and to a lesser extent pyrimidine-pyrimidone (6-4) photoproducts ((6-4)PPs), which may result in the appearance of mutations and cell death. ${ }^{4-7}$ The CPD photolesions can also arise from photosensitization, where an endogenous or exogenous photosensitizer (PS) can absorb UVA light to generate long-lived reactive species such as excited triplet states that will be the initiators of the damaging reactions. ${ }^{8,9}$ Nature has developed efficient mechanisms to repair these lesions. In this context, the nucleotide excision repair operates in humans, while in other organisms such as bacteria or plants the involvement of a photolyase reverses the damage through a photoinduced electron transfer process. ${ }^{10-13}$

Benzophenone (BP) is a well-known photosensitizing moiety that is present in a variety of drugs. ${ }^{14}$ It can induce damage to DNA, and its main target is the thymine (Thy) nucleobase. ${ }^{15-17}$ In this regard, excitation of BP with UVA light generates its triplet excited state $\left({ }^{3} \mathrm{BP} *\right)$, which can then induce formation of CPDs through a formal $[2+2]$ cycloaddition between two adjacent thymine units, or

Departamento de Química/Instituto de Tecnología Química UPV-CSIC, Universitat Politècnica de València, Camino de Vera $s / n, 46022$ València (Spain).

Electronic Supplementary Information (ESI) available: Synthesis and characterization of the uracil and thymine derivatives and the corresponding intermediates by means of ${ }^{1} \mathrm{H}$ and ${ }^{13} \mathrm{C}$ NMR and HRMS. Synthetic schemes, femtosecond transient absorption and laser flash photolysis spectra and kinetic traces. alternatively it may lead to oxetane derivatives through a triplet exciplex ${ }^{3}[\text { BP...Thy }]^{*} .{ }^{18-20}$

The photoreactivity of monomeric pyrimidine bases such as thymine or uracil (Ura) interacting with BP is highly influenced by the substituents at position $\mathrm{C} 5$ of the nucleobase, mainly due to steric hindrance. In this context, CPDs formation in solutions containing BP and Ura derivatives is completely blocked by the presence of a bulky group at the C5 position of the nucleobase. ${ }^{21}$ In connection with oxetanes, the Paternò-Büchi photoreaction between Thy and BP derivatives has been reported in the course of model studies related to the photoenzymatic repair of DNA (6-4)PPs. ${ }^{22-27}$ Interestingly, direct photolysis of some of these oxetanes results in a rare adiabatic cleavage to form ${ }^{3} \mathrm{BP} *$ and Thy in its ground state. ${ }^{23,}{ }^{26}$ This process has recently been investigated in detail for two head-to-head $(\mathrm{HH})$ and head-to-tail (HT) oxetane regioisomers obtained from 1,3dimethylthymine (DMT) and BP (see Scheme 1). ${ }^{18}$ Irradiation of any of the two isomers induces instantaneous formation of its first excited singlet state, which rapidly evolves to a singlet biradical through $\mathrm{C}-\mathrm{C}$ bond scission. For the $\mathrm{HH}$ - isomer, step (III) to reach the excited triplet exciplex ${ }^{3}[\mathrm{BP} . . \mathrm{DMT}]^{*}$ has been found to be much more efficient than for the HT-isomer, which may follow step (IV) to generate a triplet biradical that evolves to regenerate either the starting oxetane or the separated Thy and BP chromophores in the ground state. Alternatively, the triplet exciplexes are also formed from the HT oxetane, albeit to a lesser extent; these species finally dissociate to give ${ }^{3} \mathrm{BP} *$ and $\mathrm{DMT}$ in the ground state. Consequently, the adiabatic cycloreversion of the two investigated oxetanes seems to be markedly influenced by the HH- vs. the HT-regiochemistry. 


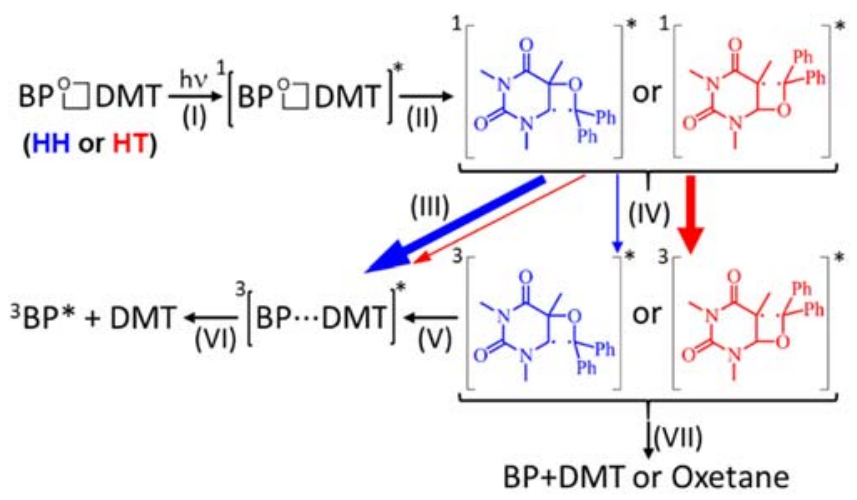

Scheme 1 Schematic representation of the photoinduced cycloreversion process of the $\mathrm{HH}$ and $\mathrm{HT}$ oxetanes composed of BP and DMT. ${ }^{18}$ For clarification, the $\mathrm{HH}$ regioisomer follows the blue arrows, while the HT oxetane follows the red ones.

With this background, the aim of the present work is to establish the generality and scope of the adiabatic cycloreversion process and to gain further insight into its mechanistic features, using a variety of oxetanes with different regiochemistries and substitution patterns at positions 1 and 5 of the nucleobase. With this goal, different oxetanes have been obtained by the intermolecular photoreaction between BP and Ura or Thy derivatives. In addition, oxetanes arising from the analogous intramolecular process between Thy and BP units covalently connected by spacers of different nature have also been studied in order to evaluate the possible influence of the linker on the photolytic splitting. Thus, the photobehavior of a variety of $\mathrm{HH}$ - and HT-oxetanes (see Fig. 1) has been investigated by means of nanosecond laser flash photolysis (LFP) and, in some cases, femtosecond transient absorption spectroscopy. As a matter of fact, the obtained results confirm the generality of the adiabatic photocleavage in Thy/BP oxetanes, as well as its dependence on the $\mathrm{HH}-$ vs. $\mathrm{HT}$ regiochemistry. Moreover, they indicate that the ring opening process is highly influenced by the nature of the substituents at positions 1 and 5 of the nucleobase.

A
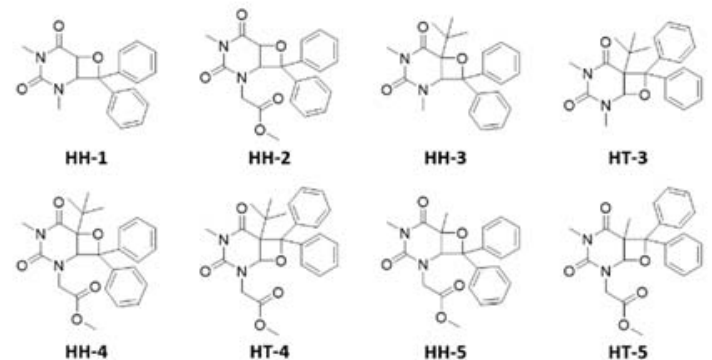

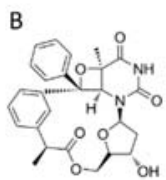

HH-6

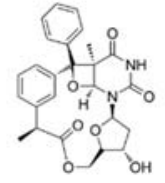

HT-6

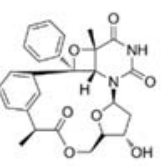

HH-7

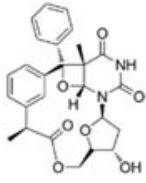

HT-7

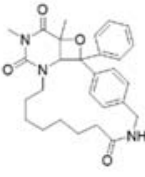

HH-8
Fig. 1 Chemical structure of the investigated systems. A) Oxetanes arising from the intermolecular photoreaction between BP and Ura (from $\mathrm{HH}-1$ to HT-4) or Thy (HH-5 and HT-5) derivatives. B) Oxetanes arising from the intramolecular photoreaction between BP and Thy units covalently linked by spacers of different nature.

\section{Results and discussion}

The photobehavior of oxetanes resulting from the intermolecular photoreaction between BP and Ura or Thy derivatives (see Fig. 1A) was studied first. In general, for all investigated systems, direct steady-state photolysis with UVC light gave rise to the starting materials BP and the Ura or Thy derivatives as the only photoproducts. The synthesis of $\mathrm{HH}-1$ has been described earlier; ${ }^{28}$ however, we have slightly modified the synthetic procedure to get the different $\mathrm{HH}$ - and $\mathrm{HT}$-regioisomers (see Scheme 2). Briefly, solutions containing $\mathrm{BP}(0.2 \mathrm{M})$ and the nucleobase derivative $(0.1$ $\mathrm{M})$ in acetonitrile were placed into Pyrex tubes and irradiated $c a .6 \mathrm{~h}$ under nitrogen in a Luzchem photoreactor emitting at $\lambda_{\max }=350 \mathrm{~nm}$ $(12 \times 8 \mathrm{~W}$ lamps). The crudes were purified by column chromatography to get the final $\mathrm{HH}$ - and/or HT-oxetanes as white solids. The synthesis of the precursor nucleobase derivatives is explained in detail in the ESI.

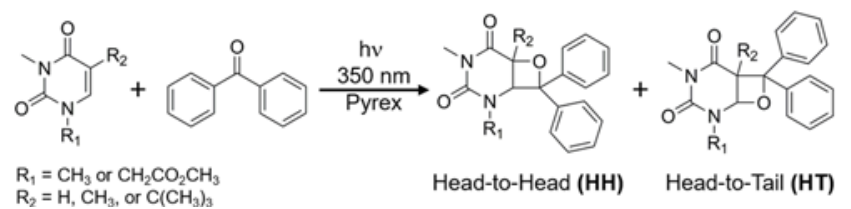

Scheme 2 Schematic representation of the photoinduced cycloreversion process of oxetanes composed of BP and DMT.

Due to the chemical instability of the uracil-derived HT-1 and HT2, which could not be isolated in pure form, only the photophysical properties of their $\mathrm{HH}$-regioisomers were investigated. Thus, nanosecond laser flash photolysis (LFP) measurements were performed upon excitation at $266 \mathrm{~nm}$ in deaerated acetonitrile, using $\mathrm{BP}$ as a reference. Under these conditions, photolysis of either $\mathrm{HH}-1$ or $\mathrm{HH}-2$ resulted in the instantaneous formation of a transient absorption peaking at $530 \mathrm{~nm}$, where ${ }^{3} \mathrm{BP} *$ displays its maximum. ${ }^{29}$ This result agrees well with the previous observations for the HH BPDMT oxetane. ${ }^{18}$ Thus, after the laser pulse, a nearly quantitative adiabatic population of ${ }^{3} \mathrm{BP} *$ was achieved for both oxetanes (see Fig. 2). The decay traces were properly fitted by a one-order exponential law with lifetimes of about $5 \mu$ s for BP and $\mathrm{HH}-1$ and shorter for $\mathrm{HH}$ 2 (ca. $2 \mu \mathrm{s}$ ). The difference in the triplet lifetimes could be associated with a faster BP triplet quenching by $\mathrm{HH}-2$ than by $\mathrm{HH}-1$.
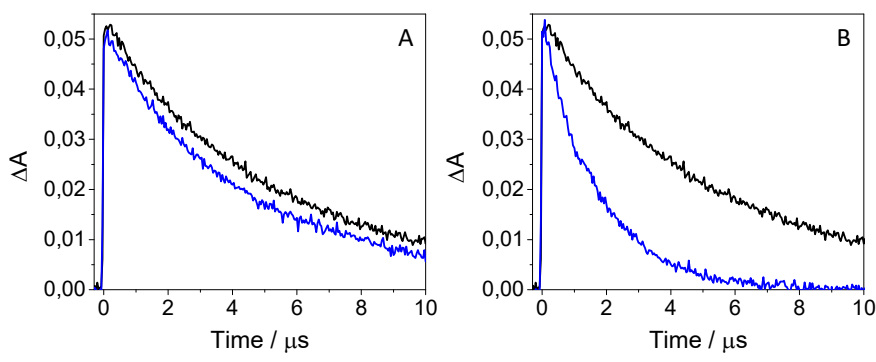
Fig. 2 LFP decay traces at $530 \mathrm{~nm}$ for A) HH-1 (blue) and BP (black), and B) HH2 (blue) and BP (black) after excitation at $266 \mathrm{~nm}$ in deaerated acetonitrile.

Since the influence of the regiochemistry on the photobehavior of the HT-uracil derivatives could not be evaluated due to their chemical instability, two additional and more stable substituted uracil oxetanes, namely $\mathrm{HH}-3$ and $\mathrm{HT}-3$, were synthesized with a bulky tert-butyl group at position 5 . In this context, LFP measurements evidenced clear differences between the two regioisomers (see Fig. 3). Analysis of the kinetic traces at $530 \mathrm{~nm}$ showed again an almost quantitative end-of-pulse adiabatic population of ${ }^{3} \mathrm{BP}^{*}$ for $\mathrm{HH}-3$, while this process was much less efficient (ca. 35\%) for HT-3. Therefore, a strong regioselectivity was observed in the photoinduced ring-opening reaction, which is in line with the results recently reported for the HH and HT BP-DMT oxetanes; ${ }^{18}$ noteworthy, in the case of 3 the difference in the degree of adiabaticity found between the $\mathrm{HH}$ - and the HT-regioisomers was markedly enhanced. Thus, the presence of a tert-butyl substituent at position 5 had little if any effect on the photoreactivity of the $\mathrm{HH}$ derivative, but it clearly affected the photobehavior of the HTisomer.

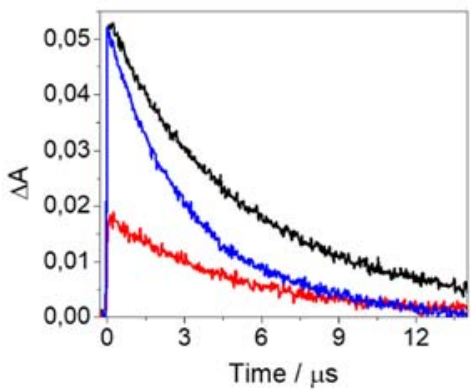

Fig. 3 LFP decay traces at $530 \mathrm{~nm}$ for BP (black), HH-3 (blue) and HT-3 (red) after excitation at $266 \mathrm{~nm}$ in deaerated acetonitrile.

In order to complete the picture on the influence of the substituents at positions 1 or 5 on the adiabatic cycloreversion of nucleobase-derived oxetanes, two additional uracil-derived compounds were synthesized, namely HH-4 and HT-4 (with a bulky tert-butyl substituent at position 5 and a methyl acetate group at position 1) as well as the corresponding Thy analogues $\mathrm{HH}-5$ and HT5. As stated above for the related compounds $\mathrm{HH}-3$ and $\mathrm{HT}-3$, the ns LFP decay traces at $530 \mathrm{~nm}$ for HH-4 and HT-4 (Fig. S11A in ESI) evidenced a remarkable regioselectivity (end-of-pulse ${ }^{3} \mathrm{BP} *$ ratio $\mathrm{ca}$. $4: 1)$ in the adiabatic cycloreversion of the investigated oxetanes. Thus, replacement of the methyl group with a methyl acetate substituent at position 1 for the tert-butyl derivatives mainly affected the adiabaticity of the HT-isomer, which decreased from $35 \%$ in HT3 to $20 \%$ in HT-4. This could be associated with a possible stabilization of the triplet biradical (see Scheme 1) by the influence of the methyl acetate moiety, which could hinder formation of the triplet exciplex (step III) thus favoring step VII to generate the starting oxetane HT-4 or the separated BP and Thy chromophores in the ground state. For the thymine derivatives HH-5 and HT-5 (Fig. S11B in ESI), a regiodifferentiation was again observed in the adiabatic ring-opening (end-of-pulse ${ }^{3} \mathrm{BP}^{*}$ ratio $c a$. 7:3), which was comparable to the results recently reported for BP-DMT oxetanes. ${ }^{18}$

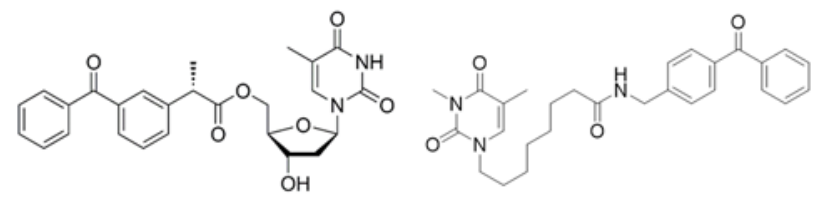

dyad 1

dyad 2

Fig. 4 Chemical structures of dyad 1 and dyad 2 .

In view of the photoreactivity observed for the nucleobasederived oxetanes as a function of the substitution at positions 1 and 5 , the photobehavior of polycyclic oxetanes (see Figure 1B) whose splitting could lead to BP and Thy chromophores covalently linked through a spacer of different nature was also investigated. Their synthesis was achieved following the reported procedures, ${ }^{26,30}$ by means of the Paternò-Büchi photoreaction between the BP and Thy units of the precursor dyads 1 and 2 (see Fig. 4). Thus, photolysis of the dyad 1 containing the BP and Thy chromophores linked through a sugar moiety resulted in the formation of $\mathrm{HH}-6, \mathrm{HT}-6, \mathrm{HH}-7$ and HT$7,{ }^{26}$ whereas $\mathrm{HH}-8$ was obtained from irradiation of dyad 2 , where BP and Thy are connected through a linear chain of ten linking atoms..$^{30}$ Steady state photolysis of oxetanes $\mathrm{HH}-6, \mathrm{HT}-6, \mathrm{HH}-7$ and $\mathrm{HT}-7$ gave rise in all cases to dyad 1 as the only photoproduct, whereas, under the same conditions, oxetane $\mathrm{HH}-8$ led cleanly to dyad 2 .

Since the lifetime of ${ }^{3} \mathrm{BP} *$ in dyad 1 was very short $(\sim 20 \mathrm{~ns}),{ }^{26}$ reliable transient absorption experiments could only be performed in the femtosecond time-scale. Under the employed experimental conditions, the degree of photodegradation was kept below $5 \%$. As it is shown in Fig. 5, excitation of the different regio- and stereoisomeric oxetanes HH-6, HT-6, HH-7 and HT-7 at $280 \mathrm{~nm}$ in acetonitrile led to the formation of the typical triplet-triplet absorption band of BP (see Fig. S12 in ESI); ${ }^{31,32}$ with maximum at $c a$. $530 \mathrm{~nm}$ with a time constant of about $9.5 \mathrm{ps}$. Accordingly, the photoinduced cycloreversion for the intramolecular oxetanes $\mathrm{HH}-6$, HT-6, HH-7 and HT-7 also operates as an adiabatic process.
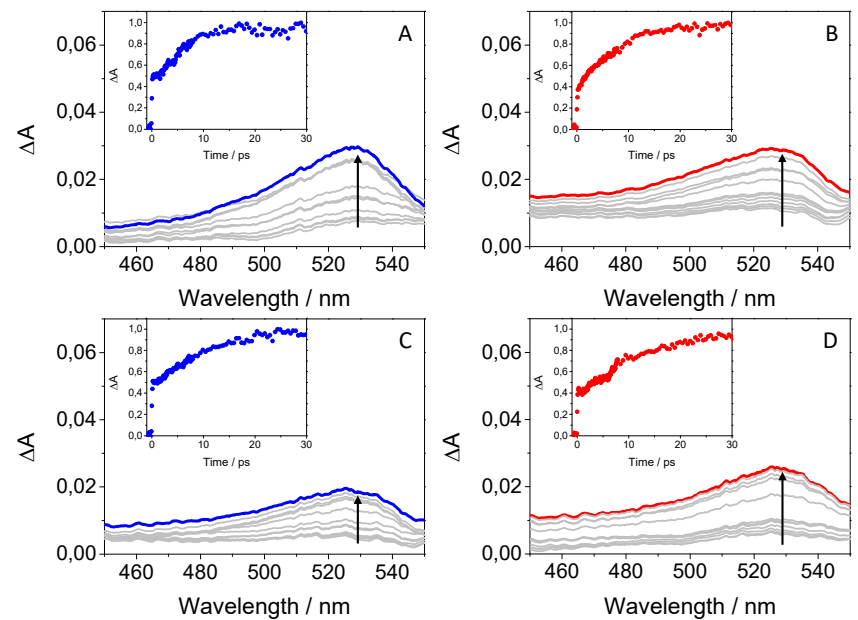

Fig. 5 Femtosecond transient absorption spectra from 0.5 to 40 ps for $\mathrm{A}) \mathrm{HH}$ $6, \mathrm{~B}) \mathrm{HT}-6, \mathrm{C}) \mathrm{HH}-7$ and D) HT-7. The insets show the kinetic traces at $530 \mathrm{~nm}$. All measurements were performed at $\lambda_{\mathrm{exc}}=280 \mathrm{~nm}$ in acetonitrile.

Finally, the photophysical properties of $\mathrm{HH}-8$ were investigated and compared to those of dyad $2 .{ }^{30}$ Kinetic analysis of the transient peaking at $530 \mathrm{~nm}$ in the ns- $\mu$ s time-scale upon LFP at $266 \mathrm{~nm}$ revealed that the decay traces in both systems could be fitted by a 
first order exponential law, with lifetimes of $c a .55$ ns. More interestingly, $\mathrm{HH}-8$ evidenced once more a complete adiabatic photoreversion process (see Fig. S13 in ESI). However, the spectra and the decay traces were noisy, due to the short triplet lifetime compared to the duration of the pulse. Hence, oxetane $\mathrm{HH}-8$ was also submitted to femtosecond transient absorption measurements ( $\lambda_{\text {exc }}$ $=280 \mathrm{~nm}$ ), which fully confirmed formation of the triplet excited state of the BP-derived chromophore with maximum at $c a .530 \mathrm{~nm}^{30}$ (see Fig. 6A and B). As previously observed for the BP-DMT regioisomers, ${ }^{18}$ an absorption at about $400 \mathrm{~nm}$ with a flat profile, which is absent for the BP-derived chromophore, was formed in $c a$. 3.5 ps (see Fig. $6 C$ and D); this can be associated with the formation of an intermediate excited triplet exciplex between the BP and Thy chromophores (see Scheme 1).
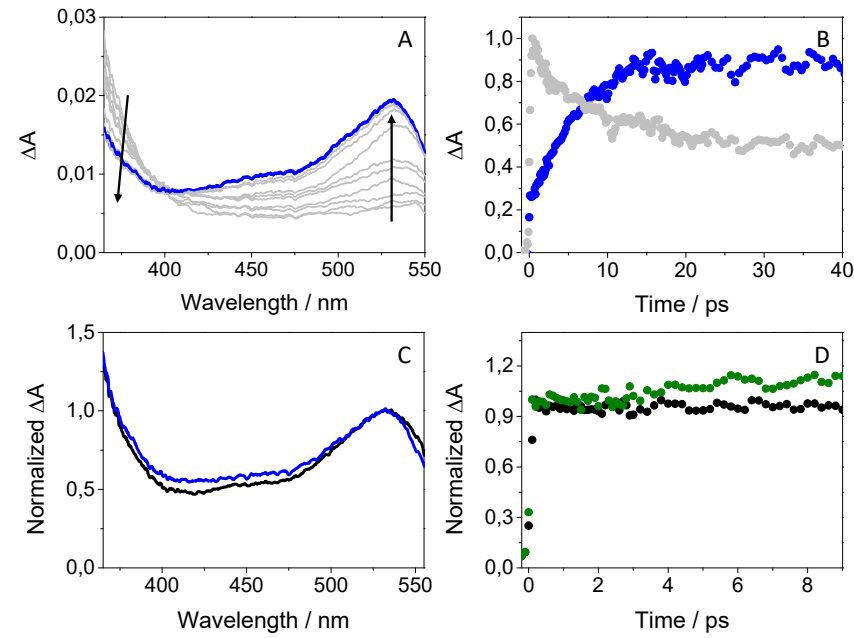

Fig. 6 Femtosecond transient absorption measurements after excitation at $280 \mathrm{~nm}$ in acetonitrile: A) spectra from 0.5 to $40 \mathrm{ps}$ and B) kinetic traces at $340 \mathrm{~nm}$ (gray) and $530 \mathrm{~nm}$ (blue) for $\mathrm{HH}-8$; C) spectra recorded at $10 \mathrm{ps}$ for the BP-derived chromophore (black) and $\mathrm{HH}-8$ (blue); D) kinetic traces at 400 $\mathrm{nm}$ for the BP-derived chromophore (black) and $\mathrm{HH}-8$ (green).

In summary, photolysis of the investigated oxetanes resulted in an adiabatic population of ${ }^{3} \mathrm{BP} *$ after ring opening. In this context, a strong regioselectivity was detected for the oxetanes 1-5, being the degree of adiabaticity much higher for the HH than for the HT isomers (see Table 1). In addition, the process was significantly affected by the substitution at position $\mathrm{N} 1$ and $\mathrm{C} 5$ of the nucleobase for the HT derivatives, whereas a less marked effect was noticed for the $\mathrm{HH}$ isomers.

Table 1 Relationship between the degree of adiabaticity and the substitution at positions $\mathrm{N} 1$ and $\mathrm{C} 5$ of the nucleobase for the photoreversion of the indicated oxetanes

\begin{tabular}{|c|c|c|c|}
\hline & Substituent at N1 & Substituent at C5 & Adiabaticity (\%) \\
\hline $\mathrm{HH}-1$ & $\mathrm{CH}_{3}$ & $\mathrm{H}$ & 100 \\
\hline $\mathrm{HH}-2$ & $\mathrm{CH}_{2} \mathrm{CO}_{2} \mathrm{CH}_{3}$ & $\mathrm{H}$ & 100 \\
\hline $\mathrm{HH}-3$ & $\mathrm{CH}_{3}$ & tert-Bu & 100 \\
\hline $\mathrm{HT}-3$ & $\mathrm{CH}_{3}$ & tert-Bu & 35 \\
\hline $\mathrm{HH}-4$ & $\mathrm{CH}_{2} \mathrm{CO}_{2} \mathrm{CH}_{3}$ & tert-Bu & 100 \\
\hline $\mathrm{HT}-4$ & $\mathrm{CH}_{2} \mathrm{CO}_{2} \mathrm{CH}_{3}$ & tert-Bu & 20 \\
\hline $\mathrm{HH}-5$ & $\mathrm{CH}_{2} \mathrm{CO}_{2} \mathrm{CH}_{3}$ & $\mathrm{CH}_{3}$ & 75 \\
\hline $\mathrm{HT}-5$ & $\mathrm{CH}_{2} \mathrm{CO}_{2} \mathrm{CH}_{3}$ & $\mathrm{CH}_{3}$ & 38 \\
\hline
\end{tabular}

Likewise, the photoinduced cleavage of the polycyclic oxetanes was found to occur as an adiabatic process. Interestingly, for the tricyclic oxetane $\mathrm{HH}-8$, a transient absorption at $\sim 400 \mathrm{~nm}$ is detected, which is ascribed to formation of the purported triplet exciplex between the linked benzophenone and thymine chromophores.

\section{Conclusions}

The UV-induced photocleavage of a variety of oxetanes arising from the inter- or intramolecular Paternò-Büchi photoreaction between BP and Ura or Thy chromophores has been investigated by means of transient absorption spectroscopy from the femtosecond to the microsecond time-scales. In all cases, an adiabatic process is observed, which leads to the BP unit in its triplet excited state. The degree of adiabaticity depends on the oxetane regiochemistry and on the substitution pattern at positions 1 and 5 of the nucleobase. In general, a nearly quantitative adiabatic cycloreversion is observed for the HH-regioisomers; by contrast, for the HT-oxetanes the process is not fully adiabatic and becomes strongly influenced by the nature of the substituents at positions 1 and 5 . The highest regiodifferentiation (4:1 ratio) is detected between HH-4 and HT-4. These results are consistent with the intermediacy of a triplet exciplex, whose formation is more favorable in the $\mathrm{HH}$-regioisomers. In summary, the adiabatic cycloreversion of oxetanes derived from aromatic ketones and pyrimidine bases appears to be a rather general process, which occurs in all the investigated compounds. Regioselectivity ( $\mathrm{HH}$ vs. $\mathrm{HT}$ ) and substitution-dependence are interesting features of this process.

\section{Experimental section}

Chemicals and reagents. 1,3-dimethyluracil, benzophenone (BP), dimethyl sulphate, lithium diisopropylamide (LDA), ethyl formate $97 \%$, thiourea, chloroacetic acid, thymine-1-acetic acid, ethyl bromoacetate, ethyl 4-bromobutyrate, were purchased from SigmaAldrich. Ethyl-8-bromooctanoate was purchased from Fluorochem. Methyl 3,3-dimethylbutanoate was purchased from Alfa-aesar. Sodium hydroxide $(\mathrm{NaOH})$, potassium hydroxide $(\mathrm{KOH})$, magnesium sulphate $\left(\mathrm{MgSO}_{4}\right)$, hydrochloric acid $37 \%(\mathrm{HCl})$ and acetonitrile spectroscopic grade were purchased from Scharlab.

Spectroscopic Techniques. The ${ }^{1} \mathrm{H}$ NMR and ${ }^{13} \mathrm{C}$ NMR spectra were recorded at 400 and $100 \mathrm{MHz}$, respectively, using a Bruker AVANCE III instrument; chemical shifts are reported in ppm.

High-resolution mass spectrometry (HRMS) was performed in an Ultra Performance Liquid Chromatography (UPLC) ACQUITY system (Waters Corp.) with a conditioned autosampler at $4{ }^{\circ} \mathrm{C}$. The separation was accomplished on an ACQUITY UPLC BEH C18 column $\left(50 \mathrm{~mm} \times 2.1 \mathrm{~mm}\right.$ i.d., $1.7 \mu \mathrm{m}$ ), which was maintained at $40{ }^{\circ} \mathrm{C}$. The analysis was performed using acetonitrile and water $(60: 40 \mathrm{v} / \mathrm{v}$ containing $0.01 \%$ formic acid) as the mobile phase with a flow rate of $0.5 \mathrm{~mL} / \mathrm{min}$, and injection volume was $5 \mu \mathrm{L}$. The Waters ACQUITY ${ }^{\mathrm{m}}$ XevoQToF Spectrometer (Waters Corp.) was connected to the UPLC system via an electrospray ionization (ESI) interface. This source was operated in positive ionization mode with the capillary voltage at 1.5 $\mathrm{kV}$ at $100^{\circ} \mathrm{C}$ and the temperature of the desolvation was $300^{\circ} \mathrm{C}$. The cone and desolvation gas flows were $40 \mathrm{~L} \mathrm{~h}^{-1}$ and $800 \mathrm{~L} \mathrm{~h}^{-1}$, respectively. The collision gas flow and collision energy applied were $0.2 \mathrm{~mL} / \mathrm{min}$ and $12 \mathrm{~V}$, respectively. All data collected in Centroid mode were acquired using Masslynx ${ }^{\mathrm{TM}}$ software (Waters Corp.). Leucine-enkephalin was used at a concentration of $500 \mathrm{pg} / \mu \mathrm{L}$ as the 
lock mass generating an $[\mathrm{M}+\mathrm{H}]^{+}$ion $(\mathrm{m} / \mathrm{z} 556.2771)$ and fragment at $\mathrm{m} / \mathrm{z} 120.0813$ and flow rate of $50 \mu \mathrm{L} / \mathrm{min}$ to ensure accuracy during the MS analysis.

Steady-state absorption spectra were recorded in a JASCO V-760 spectrophotometer. Laser Flash Photolysis (LFP) measurements were performed using a pulsed Nd:YAG L52137 V LOTIS TII at the excitation wavelength of $266 \mathrm{~nm}$. The single pulses were ca. $10 \mathrm{~ns}$ duration, and the energy was $\sim 12 \mathrm{~mJ} /$ pulse. The laser flash photolysis system consisted of the pulsed laser, a 77250 Oriel monochromator and an oscilloscope DP04054 Tektronix. The output signal from the oscilloscope was transferred to a personal computer. Absorbances of all solutions were adjusted at $\sim 0.20$ at $266 \mathrm{~nm}$ in acetonitrile. All UV and LFP measurements were done using $10 \times 10 \mathrm{~mm}^{2}$ quartz cuvettes at room temperature in deaerated conditions ( $25 \mathrm{~min} \mathrm{~N}_{2}$ bubbling), using $10 \mathrm{~mL}$ of fresh solution in order to avoid data acquisition from photodegraded products. Control experiments indicated that the degree of decomposition of all oxetanes after photolysis was lower than $5 \%$.

Femtosecond transient absorption experiments were performed using a pump-probe system. The femtosecond pulses were generated with a mode-locked Ti-Sapphire laser of a compact Libra $\mathrm{HE}(4 \mathrm{~W}$ power at $4 \mathrm{kHz}$ ) regenerative amplifier delivering $100 \mathrm{fs}$ pulses at $800 \mathrm{~nm}(1 \mathrm{~mJ} /$ pulse). The output of the laser was split into two parts to generate the pump and the probe beams. Thus, tunable femtosecond pump pulses were obtained by directing the $800 \mathrm{~nm}$ light into an optical parametric amplifier. In the present case, the pump was set at $280 \mathrm{~nm}$ and passed through a chopper prior to focus onto a rotating cell (1 $\mathrm{mm}$ optical path) containing the samples in organic solution. The white light used as probe was produced after part of the $800 \mathrm{~nm}$ light from the amplifier travelled through a computer controlled 8 ns variable optical delay line and impinge on a $\mathrm{CaF}_{2}$ rotating crystal. This white light was in turn split in two identical portions to generate reference and probe beams that then were focused on the rotating cell containing the sample. The pump and the probe beams were made to coincide to interrogate the sample. The power of the pump beam was set to $180 \mu \mathrm{W}$. Under these conditions, the degree of photodegradation of all oxetanes was lower than 5\%. A computer-controlled imaging spectrometer was placed after this path to measure the probe and the reference pulses to obtain the transient absorption decays/spectra. The experimental data were treated and compensated by the chirp using the ExciPro program.

Steady-state photolysis. Irradiations were performed in a Luzchem multilamp photoreactor emitting at $\lambda_{\max }=350 \mathrm{~nm}$ ( $12 \times 8 \mathrm{~W}$ lamps). Solutions containing the uracil or thymine derivative $(0.1 \mathrm{M})$ and $\mathrm{BP}$ $(0.2 \mathrm{M})$ were irradiated through Pyrex for $c a .6 \mathrm{~h}$; the crude products containing the $\mathrm{HH}$ - and $\mathrm{HT}$-oxetanes were purified by silica gel chromatography (hexane:ethyl acetate $80: 20 \mathrm{v} / \mathrm{v}$ ).

Oxetane HH-1. ${ }^{1} \mathrm{H}$ NMR (400 MHz, $\left.\mathrm{CDCl}_{3}\right)$ 8 7.44-7.29 (m, 10H), 5.20 (d, $J=8.8 \mathrm{~Hz}, 1 \mathrm{H}), 4.94(\mathrm{~d}, J=8.8 \mathrm{~Hz}, 1 \mathrm{H}), 3.04(\mathrm{~s}, 3 \mathrm{H}), 3.01(\mathrm{~s}, 3 \mathrm{H})$; ${ }^{13} \mathrm{C}$ NMR $\left(100 \mathrm{MHz}, \mathrm{CDCl}_{3}\right) \delta 167.0,151.7,143.3,138.7,128.7,128.4$, 128.3, 128.2, 125.9, 125.1, 96.0, 70.6, 60.7, 35.4, 27.3; HRMS (ESI): $\mathrm{m} / z$ calcd. for $\mathrm{C}_{19} \mathrm{H}_{19} \mathrm{~N}_{2} \mathrm{O}_{3}[\mathrm{M}+\mathrm{H}]^{+}: 323.1396$, found: 323.1391

Oxetane HH-2. ${ }^{1} \mathrm{H}$ NMR (400 MHz, $\left.\mathrm{CDCl}_{3}\right)$ 8 7.44-7.26 (m, 10H), 5.24 $(\mathrm{d}, J=8.8 \mathrm{~Hz}, 1 \mathrm{H}), 5.02(\mathrm{~d}, J=8.8 \mathrm{~Hz}, 1 \mathrm{H}), 4.47(\mathrm{~d}, J=17.6 \mathrm{~Hz}, 1 \mathrm{H})$, $3.77(\mathrm{~s}, 3 \mathrm{H}), 3.37(\mathrm{~d}, J=17.6 \mathrm{~Hz}, 1 \mathrm{H}), 3.06(\mathrm{~s}, 3 \mathrm{H}) ;{ }^{13} \mathrm{C} \mathrm{NMR}(100 \mathrm{MHz}$, $\left.\mathrm{CDCl}_{3}\right) \delta 168.9,166.6,151.9,142.5,138.4,128.7,128.5,128.4,126.1$, 125.4, 95.3, 70.2, 59.4, 52.7, 48.0, 27.5; HRMS (ESI): $\mathrm{m} / \mathrm{z}$ calcd. for $\mathrm{C}_{21} \mathrm{H}_{21} \mathrm{~N}_{2} \mathrm{O}_{5}[\mathrm{M}+\mathrm{H}]^{+}:$381.1450; found: 381.1446 .
Oxetane HH-3. ${ }^{1} \mathrm{H}$ NMR $\left(400 \mathrm{MHz}, \mathrm{CD}_{3} \mathrm{CN}\right)$ 8 7.41-7.23 (m, 10H), 4.94 $(\mathrm{s}, 1 \mathrm{H}), 3.21(\mathrm{~s}, 3 \mathrm{H}), 2.70(\mathrm{~s}, 3 \mathrm{H}), 0.98(\mathrm{~s}, 9 \mathrm{H}) ;{ }^{13} \mathrm{C} \mathrm{NMR}(100 \mathrm{MHz}$, $\left.\mathrm{CDCl}_{3}\right) \delta$ 169.7, 152.0, 144.2, 139.0, 128.3, 127.8, 127.6, 125.2, 124.4, 91.1, 83.5, 61.5, 35.8, 29.7, 27.4, 24.6; HRMS (ESI): $\mathrm{m} / \mathrm{z}$ calcd. for $\mathrm{C}_{23} \mathrm{H}_{27} \mathrm{~N}_{2} \mathrm{O}_{3}[\mathrm{M}+\mathrm{H}]^{+}$: 379.2022; found: 379.2027 .

Oxetane HT-3. ${ }^{1} \mathrm{H}$ NMR $\left(400 \mathrm{MHz}, \mathrm{CD}_{3} \mathrm{CN}\right)$ 8 7.84-7.20 (m, 10H), 5.84 $(\mathrm{s}, 1 \mathrm{H}), 3.17(\mathrm{~s}, 3 \mathrm{H}), 2.66(\mathrm{~s}, 3 \mathrm{H}), 0.96(\mathrm{~s}, 9 \mathrm{H}) ;{ }^{13} \mathrm{C} \mathrm{NMR}(100 \mathrm{MHz}$, $\left.\mathrm{CDCl}_{3}\right) \delta 169.1,153.0,144.5,128.2,127.7,127.4,127.2,125.9,89.5$, 84.3, 66.0, 35.9, 34.2, 29.7, 27.5; HRMS (ESI): $\mathrm{m} / \mathrm{z}$ calcd. for $\mathrm{C}_{23} \mathrm{H}_{27} \mathrm{~N}_{2} \mathrm{O}_{3}[\mathrm{M}+\mathrm{H}]^{+}$: 379.2022; found: 379.2026 .

Oxetane HH-4. ${ }^{1} \mathrm{H}$ NMR $\left(400 \mathrm{MHz}, \mathrm{CDCl}_{3}\right) \delta$ 7.37-7.23 (m, 10H), 4.97 $(\mathrm{s}, 1 \mathrm{H}), 4.84(\mathrm{~d}, J=17.6 \mathrm{~Hz}, 1 \mathrm{H}), 3.82(\mathrm{~s}, 3 \mathrm{H}), 3.73(\mathrm{~d}, J=17.6 \mathrm{~Hz}, 1 \mathrm{H})$, $2.84(\mathrm{~s}, 3 \mathrm{H}), 1.10(\mathrm{~s}, 9 \mathrm{H}) ;{ }^{13} \mathrm{C} \mathrm{NMR}\left(100 \mathrm{MHz}, \mathrm{CDCl}_{3}\right) \delta 169.8,169.1$, 152.1, 143.7, 139.1, 128.7, 128.4, 127.8, 125.4, 124.6, 90.6, 83.6, 59.7, 52.6, 48.3, 36.2, 27.5, 24.4; HRMS (ESI): $\mathrm{m} / \mathrm{z}$ calcd. for $\mathrm{C}_{25} \mathrm{H}_{29} \mathrm{~N}_{2} \mathrm{O}_{5}[\mathrm{M}+\mathrm{H}]^{+}:$437.2076; found: 437.2071.

Oxetane HT-4. ${ }^{1} \mathrm{H}$ NMR $\left(400 \mathrm{MHz}, \mathrm{CDCl}_{3}\right) \delta$ 7.79-7.19 (m, 10H), 5.81 $(\mathrm{s}, 1 \mathrm{H}), 4.80(\mathrm{~d}, J=17.6 \mathrm{~Hz}, 1 \mathrm{H}), 4.07(\mathrm{~d}, J=17.6 \mathrm{~Hz}, 1 \mathrm{H}), 3.80(\mathrm{~s}, 3 \mathrm{H})$, $2.79(\mathrm{~s}, 3 \mathrm{H}), 1.04(\mathrm{~s}, 9 \mathrm{H}) ;{ }^{13} \mathrm{C} \mathrm{NMR}\left(100 \mathrm{MHz}, \mathrm{CDCl}_{3}\right) \delta 169.2,168.9$, 152.0, 142.6, 141.4, 128.1, 127.8, 127.5, 127.3, 127.1, 126.0, 89.8, 83.3, 66.0, 52.5, 47.1, 36.1, 27.8, 27.3; HRMS (ESI): $\mathrm{m} / \mathrm{z}$ calcd. for $\mathrm{C}_{25} \mathrm{H}_{29} \mathrm{~N}_{2} \mathrm{O}_{5}[\mathrm{M}+\mathrm{H}]^{+}:$437.2076; found: 437.2073.

Oxetane HH-5. ${ }^{1} \mathrm{H}$ NMR $\left(400 \mathrm{MHz}, \mathrm{CDCl}_{3}\right) \delta$ 7.38-7.25 (m, 10H), 4.78 $(\mathrm{d}, J=17.6 \mathrm{~Hz}, 1 \mathrm{H}), 4.64(\mathrm{~s}, 1 \mathrm{H}), 3.79(\mathrm{~s}, 3 \mathrm{H}), 3.58(\mathrm{~d}, J=17.6 \mathrm{~Hz}, 1 \mathrm{H})$, $2.85(\mathrm{~s}, 3 \mathrm{H}), 1.76(\mathrm{~s}, 3 \mathrm{H}) ;{ }^{13} \mathrm{C} \mathrm{NMR}\left(100 \mathrm{MHz}, \mathrm{CDCl}_{3}\right) \delta 169.0,168.8$, $151.9,143.8,138.6,128.7,128.4,128.1,125.6,125.1,91.3,65.3$, 52.7, 48.3, 27.5, 23.7; HRMS (ESI): $m / z$ calcd. for $\mathrm{C}_{22} \mathrm{H}_{23} \mathrm{~N}_{2} \mathrm{O}_{5}[\mathrm{M}+\mathrm{H}]^{+}$: 395.1607; found: 395.1607 .

Oxetane HT-5. ${ }^{1} \mathrm{H}$ NMR $\left(400 \mathrm{MHz}, \mathrm{CDCl}_{3}\right) \delta$ 7.55-7.18 (m, 10H), 5.29 $(\mathrm{s}, 1 \mathrm{H}), 4.64(\mathrm{~d}, J=23.6 \mathrm{~Hz}, 1 \mathrm{H}), 4.04(\mathrm{~d}, J=23.6 \mathrm{~Hz}, 1 \mathrm{H}), 3.78(\mathrm{~s}, 3 \mathrm{H})$, $2.78(\mathrm{~s}, 3 \mathrm{H}), 1.52(\mathrm{~s}, 3 \mathrm{H}) ;{ }^{13} \mathrm{C} \mathrm{NMR}\left(100 \mathrm{MHz}, \mathrm{CDCl}_{3}\right) \delta 169.1,151.7$, $141.8,141.1,128.3,128.0,127.7,127.6,125.3,125.1,90.5,87.1$, 52.5, 46.1, 27.8, 20.1; HRMS (ESI): $\mathrm{m} / \mathrm{z}$ calcd. for $\mathrm{C}_{22} \mathrm{H}_{23} \mathrm{~N}_{2} \mathrm{O}_{5}[\mathrm{M}+\mathrm{H}]^{+}$: 395.1607, found: 395.1606 .

\section{Conflicts of interest}

There are no conflicts to declare.

\section{Acknowledgements}

Financial support from the Spanish Government (RYC-2015-17737 and CTQ2017-89416-R) and from the Consellería d'Educació Cultura i Esport (PROMETEO/2017/075 and GRISOLIAP/2017/005) is gratefully acknowledged.

\section{References}

1 K. H. Kraemer, Proc. Natl. Acad. Sci. USA, 1997, 94, 11-14.

2 J.-S. Taylor, Acc. Chem. Res., 1994, 27, 76-82.

3 F. Urbach, J. Photochem. Photobiol. B, 1997, 40, 3-7.

4 H. Mukhtar and C. A. Elmets, Photochem. Photobiol., 1996, 63, 356-357.

5 B. M. Sutherland, Photochem. Photobiol., 1996, 63, 375-377.

6 S. Tommasi, M. F. Denissenko and G. P. Pfeifer, Cancer Res., 1997, 57, 4727-4730.

7 J. Cadet, A. Grand and T. Douki, Top. Curr. Chem., 2015, 356, 249275. 
8 J. Cadet, S. Mouret, J. L. Ravanat and T. Douki, Photochem. Photobiol., 2012, 88, 1048-1065.

9 B. Epe, M. Pflaum and S. Boiteux, Mutat. Res., 1993, 299, 135145.

10 J. Li, Z. Liu, C. Tan, X. Guo, L. Wang, A. Sancar and D. Zhong, Nature, 2010, 466, 887-890.

11 T. Todo, H. Ryo, K. Yamamoto, H. Toh, T. Inui, H. Ayaki, T. Nomura and M. Ikenaga, Science, 1996, 272, 109-112.

12 T. Todo, H. Takemori, H. Ryo, M. Ihara, T. Matsunaga, O. Nikaido, K. Sato and T. Nomura, Nature, 1993, 361, 371-374.

13 T. Todo, H. Tsuji, E. Otoshi, K. Hitomi, S.-T. Kim and M. Ikenaga, Mutat. Res., 1997, 384, 195-204.

14 K. Surana, B. Chaudhary, M. Diwaker and S. Sharma, Med. Chem. Commun., 2018, 9, 1803-1817.

15 F. Bosca and M. A. Miranda, J. Photochem. Photobiol. B, 1998, 43 1-26.

16 T. Delatour, T. Douki, C. D'Ham and J. Cadet, J. Photochem. Photobiol. B, 1998, 44, 191-198.

17 J. E. Rogers and L. A. Kelly, J. Am. Chem. Soc., 1999, 121, 3854 3861.

18 A. Blasco-Brusola, M. Navarrete-Miguel, A. Giussani, D. RocaSanjuán, I. Vayá and M. A. Miranda, Phys. Chem. Chem. Phys., 2020, 22, 20037-20042.

19 M. C. Cuquerella, V. Lhiaubet-Vallet, F. Bosca and M. A. Miranda, Chem. Sci., 2011, 2, 1219-1232.

20 P. Miró, M. Gómez-Mendoza, G. Sastre, M. C. Cuquerella, M. A. Miranda and M. L. Marín, Chem. Eur. J., 2019, 25, 7004-7011.

21 V. Vendrell-Criado, V. Lhiaubet-Vallet, M. Yamaji, M. C. Cuquerella and M. A. Miranda, Org. Biomol. Chem., 2016, 14, 4110-4115.

22 S. Encinas, N. Belmadoui, M. J. Climent, S. Gil and M. A. Miranda, Chem. Res. Toxicol., 2004, 17, 857-862.

23 A. Joseph and D. E. Falvey, J. Am. Chem. Soc., 2001, 123, 31453146.

24 A. Joseph, G. Prakash and D. E. Falvey, J. Am. Chem. Soc., 2000, 122, 11219-11225.

25 G. Prakash and D. E. Falvey, J. Am. Chem. Soc., 1995, 117, 1137511376.

26 N. Belmadoui, S. Encinas, M. J. Climent, S. Gil and M. A. Miranda, Chem. Eur. J., 2006, 12, 553-561.

27 S.-T. Kim, K. Malhotra, C. A. Smith, J.-S. Taylor and A. Sancar, J. Biol. Chem., 1994, 269, 8535-8540.

28 A. Joseph and D. E. Falvey, Photochem. Photobiol. Sci., 2002, 1 632-635.

29 J. A. Bell and H. Linschitz, J. Am. Chem. Soc., 1963, 85, 528-532.

30 A. Blasco-Brusola, I. Vayá and M. A. Miranda, J. Org. Chem., 2020, Accepted, DOI: 10.1021/acs.joc.0c02088

31 N. Tamai, T. Asahi and H. Masuhara, Chem. Phys. Lett., 1992, 198, 413-418.

32 W. M. Kwok, X. Guan, L. M. Chu, W. Tang and D. L. Phillips, J. Phys. Chem. B, 2008, 112, 11794-11797. 